\title{
ANCIENT DNA RESEARCH: ONGOING CHALLENGES AND CONTRIBUTION TO MEDICAL SCIENCES
}

\author{
Ozge Uysal Yoca ${ }^{1}$, Hande Efe ${ }^{1}$, Zeynep Yuce ${ }^{1}$,
}

${ }^{1}$ Dokuz Eylul University, Institute of Health Sciences, Medical Biology and Genetics, Izmir, Turkey

\author{
Address for Correspondence: Ozge Uysal Yoca, M.Sc., E-mail: ozgeuysal6@gmail.com \\ Received: 08.01.2021; Accepted: 11.04.2021; Available Online Date: 27.05.2021 \\ @C Copyright 2021 by Dokuz Eylül University, Institute of Health Sciences - Available online at https://dergipark.org.tr/en/pub/jbachs
}

Cite this article as: Uysal-Yoca O, Efe H, Yuce Z. Ancient DNA Research: Ongoing Challenges and Contribution to Medical Sciences. J Basic Clin Health Sci 2021; 2: 182-189.

\begin{abstract}
Life gave rise on our planet 3-4 billion years ago and since then, living organisms (from one cell to multicellular organisms) have undergone many genetic, phenotypic and communal changes. Scientists have been able to shed light on only a small part of this evolutionary process, but with the development of new techniques our knowledge is expanding day by day. For the past 30 years ancient DNA studies have aided us in understanding the molecular basis of the changes observed in living organisms. Ancient DNA (aDNA) is the genetic material obtained from biological remains (bones, teeth, plant seeds, etc.) acquired from archaeological and paleontological excavations. In the present review, molecular studies carried out to date, contributions of ancient DNA to medical sciences, as well as basic problems encountered in obtaining and using aDNA have been discussed.
\end{abstract}

Keywords: ancient DNA, medical sciences, aDNA researches

\section{INTRODUCTION}

Ancient DNA (aDNA) research has been an active field in molecular biology for over 30 years. Developing techniques has led to detailed studies that shed light on our past, future and interactions with the world we live in. Secrets of our ancient ancestors are revealed by working with archeological/paleontological samples, answering questions on our shared life on our planet. The recovery of DNA sequences from skeletal remains such as bones and teeth, reveal the genetic and evolutionary history of man; while also shedding light on the migration routes and demographic processes populations have undergone. In addition, aDNA studies have revealed environmental crises affecting population bottlenecks and demographic dynamics of several megafauna species up until their extinction.
Data from ancient DNA is also a very important tool to draw conclusions about the mode and pace of evolutionary processes for reconstructing the phenotypic properties of prehistoric groups, and to consider the relative effects of selection and demography in changing allele frequencies within human populations (1). In addition to human studies, investigations on animals and plants are also extensively performed in aDNA research. These studies contribute to our knowledge on evolutionary processes occurring in animals and plants, extinct species, changes in genetic diversity in populations, the interaction of changes in the population with geographic location and determination of phylogenetic relationships (2). 
The first report on aDNA was published in 1984, describing the genetic structure of a guagga (an extinct species considered to be the ancestor of the horse family) taken from the Museum of Natural History in Mainz, Germany. The researchers succeeded in sequencing the short DNA fragments they had amplified by molecular cloning (3). In the early 1980's, amplification of DNA (a prerequisite step before sequencing) isolated from ancient finds was carried out by cloning, which was both time consuming and laborious. However, with the development and use of the polymerase chain reaction (PCR) technique in 1985, DNA sequencing and ancient DNA studies accelerated. In 1985, DNA sequencing was performed on a tissue sample extracted from a 2400 year old mummy on display in a museum in Egypt (4). With the use of PCR, aDNA studies have been carried out from a variety of samples such as tissue from mummies, human and animal bones, plant remains and animal tissues obtained from archaeological studies.

The first international Ancient DNA Meeting, in which advances in aDNA studies were presented, was held in 1991 with the participation of 60 researchers. Progress in the field of molecular biological impacted ancient DNA studies tremendously. The entire genome sequence of Haemophilus influenzae was published in 1995 (5); followed by the first whole genome sequence of a eukaryote -Saccharomyces cerevisiae- in 1996 (6). The development of second generation sequencing in 2005 was a breakthrough in which much more sensitive results were obtained in less time and with less workforce when compared to Sanger sequencing (7). With the development of new and better sequencing methods and molecular techniques, studies of aDNA extracted from older samples became feasible. The oldest sample studied to date by using new generation Illumina and Helicos sequencing, is on a horse sample dating back 700,000 years $(8)$.

Even with the tremendous advancements in sequencing techniques, DNA isolation from ancient samples remains to be the most crucial step in any research involving aDNA. aDNA molecules are highly fragmented because of degradation and environmental factors, discussed below. Classical DNA extraction methods do not provide sufficient amounts of workable quality DNA, when used on ancient remains. Modifications of conventional methods has led to isolation of aDNA in amounts and quality suitable for analyses. There are many conventional DNA extraction methods, among which solid phase extraction and organic extraction are the most widely used. Spin-columns, containing a silica gel/silica beads and chaotropic salts are commonly used in solid phase DNA extraction. Chaotropic salts denatures double stranded DNA by abolishing the hydrogen bonds between the strands; leading to the binding of the DNA to silica (9). After a washing step with ethanol to remove chaotropic salts and other unnecessary components; the DNA is eluted from the column by rehydration with aqueous low salt solution. Organic extraction is performed with the addition and incubation of multiple different chemical solutions. It includes a lysis step, a phenol chloroform extraction, an ethanol precipitation, and washing steps. The samples are usually lysed using heat, DTT (ditiotreitol) and SDS (sodium dodecyl sulfate); proteins digested by the addition of Proteinase $\mathrm{K}$. DNA is then separated from cellular components by phenol-chloroform- isoamyl alcohol (PCIA). The addition of PCIA results in two layers: the DNA containing aqueous phase (top) and the organic phase (bottom). It is important that to remove all organic extraction reagents, otherwise DNA will be degraded by phenol. Although organic extraction is widely used and very efficient, organic solvent contamination may lead to problems if not done carefully (10).

Modifications of both these methods are widely used in aDNA research. aDNA extracted from ancient tissues is fragmented and damaged, with the degree of DNA fragmentation increasing with sample age (discussed below). It is important to use protocols in which these short fragments are not lost. Dabney and Meyer reported a silica-based aDNA extraction protocol used in combination with a single-stranded DNA library preparation, which is suitable for the recovery of short DNA fragments ( $35 \mathrm{bp}$ ) from hard samples such as bones and teeth. Following pulverization of the bone, the sample is treated with an extraction buffer containing EDTA and Proteinase $\mathrm{K}$. The DNA released from the dissolved sample is bound to silica in the presence of guanidine hydrochloride and isopropanol; followed by a low-salt buffer elution $(11,12)$. The main modifications of conventional methods they had made include a binding buffer containing guanidine hydrochloride, sodium acetate, and isopropanol; an increase in the 
volume of the binding buffer used and to use silica spin columns with reservoirs enabling large loading volumes. Despite the challenges in obtaining workable samples, aDNA research is progressing in parallel with the development of molecular techniques and it remains at the intersection of our understanding of medical sciences, the molecular basis of the changes observed in living organisms and disease evolution.

\section{Contributions of aDNA to medical sciences}

Ancient DNA studies have aided the scientific community to identify diseases experienced by historic populations and the microorganisms that cause these diseases. These studies play a pivotal role in understanding how contagious diseases have changed from past to present. Hepatitis $\mathrm{B}$, which has a global prevalence of $3.6 \%$, is transmitted by blood and/or body fluids. The presence of the hepatitis B virus (HBV) in humans is detected as early as the Bronze Age. aDNA studies done on 12 samples from Bronze-Medieval ages revealed that HBV infection spred throughout Eurasia for thousands of years due to human migration. The discovery of ancient viral sequences was able to demonstrate the origin and early diversification of HBV. These results not only addressed paleo-epidemiological questions; they also enabled our understanding of natural-cultural changes including migrations and medical practices (13). HBV still exists today albeit a low prevalence, yet aDNA studies have revealed the disease caused great losses in the past.

Many studies have been conducted to investigate the Plague, which has caused great loss especially in the Middle Ages. Traces of the bacteria Yersinia pestis which caused the plague- were tracked with aDNA studies. Human tooth samples (from Asia and Europe) were studied and the Yersinia pestis genome was detected in samples that were 3000 years than the older than the first record of the disease (541-544 $A D$ ) in historical archives (14). The presence of microorganisms such as Mycobacterium tuberculae, Mycobacterium leprae, as well as Yersina pestis, was also demonstrated by aDNA studies on ancient skeletons (1). In addition, evolutionary changes in a strain of Yersinia pestis transmitted through fleas has been reported (15). Supplementing the examination of the history/evolution of disease and diseasecausing microorganisms; comparison studies with modern humans have also been conducted. aDNA extracted from Neanderthal dental calculus, revealed that Neanderthal microbiota resembles chimpanzee specimens when compared to modern humans and contains less potential pathogenic gram negative species (16).

Infectious diseases are not the only group of diseases detected and examined by aDNA. Cancer has also been a focus of interest. Genetic alterations that may play a role in cancer pathogenesis were detected in 2500 year old bone samples, immunohistochemically suspicious of metastatic prostate cancer. Although short sequences of the GADD153 DNA repair gene and p53 tumor suppressor gene were obtained, no mutations were detected in these genes. However, after bisulfite-treatment of the DNA extracted from the bone, hypermethylated promoter sequences of the p14ARF tumor suppressor gene was detected by methylation-specific PCR. This study not only showed that it was possible to detect tumorigenetically important genes in aDNA samples; but also epigenetically modified DNA (17).

In another report, mutations in ancient genes were scanned by bioinformatics and the correlation between cancer-causing mutations and rapidly evolving genes were investigated. The investigators concluded that cancer-causing mutations in homologue genes, evolutionary go back even before multicellularity (18).

One of the most striking and interesting aDNA study carried out so far is from the remains of a human who was found buried in ice on the Austria-Italy border and later called the Ötzi-ice man. It is thought that Ötzi lived in the Copper Age, approximately 5,300 years ago. His clothes, his latest meal, cultural artefacts were all subject to extensive research. Along with the developing technology, his diseases and cause of death were also revealed. In 2011, the entire genome sequence of Ötzi was reported. His DNA sequence revealed that this individual who died 5,300 years ago was prone to heart and vascular diseases. In addition, traces of Borrelia burgdorferi bacteria causing Lyme disease were found, making Ötzi the first Lyme patient known in history. It has also been suggested that he had a 0 blood group and was a lactose intolerant individual (19). In addition, it has been determined that Ötzi had hooked parasites in his intestines and a genetic predisposition for gastrointestinal and cardiovascular diseases (20). 
Table 1. Ancient DNA damage (26)

\begin{tabular}{|l|l|l|}
\hline Oxidative & Breaks of DNA strands & Phosphodiester backbone cleavage \\
\hline & & $\begin{array}{l}\text { Baseless site formation through } \\
\text { depurination }\end{array}$ \\
\hline $\begin{array}{l}\text { Microorganism nucleases } \\
\text { create DNA degredation in } \\
\text { the postmortem cell }\end{array}$ & Breaks of DNA Strands & Sugar backbone breakage by b-elimination \\
\hline Crosslinks of DNA & $\begin{array}{l}\text { Alkylation cause } \\
\text { interstrand crosslinks }\end{array}$ & $\begin{array}{l}\text { Prevention of endogenous template } \\
\text { amplification }\end{array}$ \\
\hline & $\begin{array}{l}\text { Maillard Reaction cause } \\
\text { intermolecular crosslinks }\end{array}$ & Contamination risk increase \\
\hline Hydrolysis & $\begin{array}{l}\text { Miscoding lesions } \\
\text { formation }\end{array}$ & $\begin{array}{l}\text { incorporation of amiss bases through } \\
\text { amplification }\end{array}$ \\
\hline
\end{tabular}

Berens et al. analyzed 147 aDNA samples to study the estimated the burden of disease in 3180 gene regions. As the result of this large scale research (in terms of aDNA), it was found that the risk for hereditary diseases in ancient human populations and modern-humans are similar. However, the results also suggest that the general genomic health of Altai Neanderthals were $97 \%$ worse than modern humans, making them more prone to chronic disease (21).

Research on ancient mitochondria DNA (mtDNA) has also gained traction. A recent study conducted by Toncheva D. et.al found several mutations in ancient mtDNA samples that are associated with modern mtDNA diseases. Most of these mutations are located within the tRNA coding regions. Similar research on ancient pathogenic mtDNA variants has the potential to expand understanding of the roots of these diseases and their effects on human population (22). Ancient human remains are generally hard samples such as bone and teeth allowing the study of chronic skeleton disorders. Paget's disease (PDB) which usually effects people who older than 55 years, has been reported in bones in England dating back to the Roman period (23) Six skeletons from North West of England, dating to medieval times, were reported to show extensive pathological changes resembling PDB. Paleoproteomic analysis of these bones identified the sequestosome 1 protein (p62) -a protein central to the pathophysiology of PDB- as one of the few noncollagenous preserved in these samples. Western blot analysis indicated p62 abnormalities, however sequencing of aDNA excluded contemporary PDB-associated p62 mutations. In addition, ancient miRNAs were found to be preserved in an osteosarcoma from one of the skeletons, and the presence miR-16 expression reported in contemporary PDB-associated bone tumors was verified (24)

In addition, aDNA is also used in forensic medicine for the clarification of criminal events in history. One of the most impressive examples is the case of Italian humanist poet and intellectual Francesco Petrarca (1304-1374). Ancient mtDNA (mitochondrial DNA) analysis from teeth and rib samples revealed that the skull belongs to a woman and the body to a man. While the body in fact belongs to Petrarca, his skull has been stolen and replaced with a woman's (25).

\section{Challenges in ancient DNA research}

Ancient DNA research has been ongoing since 1980s. This field is particularly challenging in terms of protecting the samples which are exposed to environmental degrading agents and conditions. Furthermore, aDNA studies are a very demanding study field for researchers hence laboratory conditions require extreme sensitivity. Samples are exposed to many different factors from the excavation site to the laboratory. Degradation and contamination are the two main factors complicating aDNA research. While degradation causes DNA fragmentation, contamination interferes with sequence analysis.

\subsection{Degradation}

Although DNA is a stable molecule when compared to other macromolecules, this chemical stability is limited. Chemical reactions such as hydrolysis and oxidation cause disruptions in DNA structure and negatively effect the recovery of DNA fragments (Table 1) (26). 


\subsubsection{Oxidative stress}

As a result of catabolic reactions occurring in aerobic cells, oxygen radicals (superoxide radicals, hydrogen peroxide, hydroxyl radicals) are formed, leading to DNA damage (27). Oxygen radicals cause modifications of pyrimidines/purins and sugar residues, abasic regions and molecular cross-links (4, 28). Leakage from the mitochondrial electron transport chain is the main intracellular source of these radicals which damage the DNA by creating oxidative stress in living organisms. Other intracellular processes also contribute to reactive oxygen species formation. Radicals forming and leaking during death and by microorganisms in the post-mortem stage continues to damage DNA, causing fragmentation $(4,29)$. DNA oxidation occurs most often in guanine residues. Oxidized guanine transforms to 8-hydroxyguanine or 2,6-diamino-4hydroxy-5-formamidopyrimidine (28). These transformations are usually repaired in living organisms; however, there is no repair of ancient DNA. 8-hydroxyguanine and 2,6-diamino-4-hydroxy5-formamidopyrimidine, 5-hydroxy-5methylhydantoin (5-OH-5-MeHyd) and 5hydroxyhydantoin (5-OH-Hyd) and other metabolites that are formed by oxidation, are capable of blocking Taq DNA polymerase during polymerase chain reactions; further complicating analyses of aDNA (4, 30).

\subsubsection{Hydrolytic damage}

aDNA is constantly effected by destructive processes that cause hydrolysis of base and sugar residues and breaks in the sugar-phosphate backbone of DNA. 2000-10000 lesions/day are formed in the genome of each human cell by depurination (30). However, unlike living cells, repair mechanisms do not exist post-mortem DNA. Although some conditions may increase the chance of DNA to remain substantially intact, studies have shown that molecules shrink to about a hundred base pairs and are heavily affected by enviormental changes (31).

The first systematic study to investigate the quality ancient DNA was performed by Pääbo et al. in 1989 (31). They showed that DNA extracted from samples $4-13,000$ years of age were almost always fragmented into $40-500$ bp pieces. This observation has been confirmed by many subsequent studies, leading to an established understanding that DNA extracted from ancient remains is nearly always fragmented. In vitro experiments using modern DNA, suggest that hydrolytic depurination and the resulting $\beta$-elimination is the main culprit for the fragmentation observed in ancient DNA samples. $(11 ; 31 ; 32,33)$. A hydrolysis reaction in the DNA molecule, leads to the destabilization of the glycosidic bond between bases and results in abasic regions and single chain breaks (34). Base modifications in DNA arise as a result of deamination leading to conversions of adenine to hypoxanthine, cytosine to uracil, 5- methylcytosine to thymine and guanine to xanthine. In particular, hypoxanthine, uracil, thymine, and xanthine are formed by the hydraulic loss of amino groups of adenine, cytosine, 5-methylcytosine and guanine bases, respectively (Figure 1). Uracil, thymine and hypoxanthine formed by deamination reactions, result in false base pairing during PCR ( $G$ instead of $A$ and $T$ instead of $C$ ); causing errors in amplified sequences of aDNA (30).

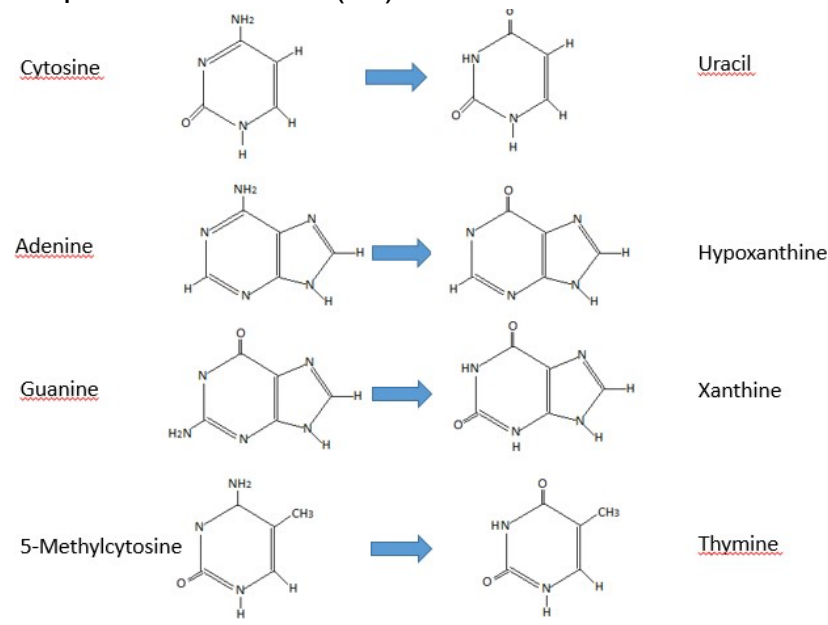

Figure 1. Deamination reaction of Cytosine, Adenine, Guanine and 5-Methylcytosine bases respectively.

\subsubsection{Degradations caused by microorganisms}

Following cellular death, DNA is degraded by endogenous nucleases, followed by spontaneous hydrolysis and oxidation. In addition to these chemical reactions, post-mortem DNA is also degraded by soil invertebrates and microorganisms. As a result, shortening of then DNA fragments and decrease in the amount of DNA is observed. Such degradations are prone to cause errors during amplification of ancient DNA samples $(5,26)$.

\subsubsection{Degradation of aDNA by environmental factors}

Bone samples unearthed during the excavation works are exposed to different temperatures, humidity and $\mathrm{pH}$ as a result of being buried underground for thousands of years. While the changing ambient 
conditions cause morphological disruptions (breakage, cracking, fragmentation) in the bones, it also causes disruptions in aDNA. These damages are caused by the sun, temperature, humidity and $\mathrm{pH}$, which are all considered as environmental factors. Changes in temperature break chemical bonds within the DNA molecule. Temperature is an important factor in ancient DNA studies. DNA degradation rate increases at high temperatures; whereas studies have shown that DNA is preserved at low temperatures. DNA structure deterioration is especially observed in the samples taken from regions with hot climates. Degradation will occur in aDNA, if samples are exposed to temperature changes after excavated. aDNA obtained from samples taken from a cave was reported to be better preserved because of constant temperature and humidity throughout the years (35).

Humidity is another environmental factor involved in the preservation of aDNA. Moisture leads to hydrolytic and oxidative damage in DNA. Bones are porous and when exposed to moisture, $\mathrm{H} 2 \mathrm{O}$ accumulates in the pores and creates favorable conditions for the growth of microorganisms leading to contamination as well as degradation $(36,37,38)$. In addition to humidity and temperature, soil type and $\mathrm{pH}$ are also parameters need to be considered in aDNA studies. Bone samples obtained from excavation works are generally in direct contact with the soil. Soil acidity, calcium content and heavy metals (iron, aluminum, manganese, etc.) cause deterioration in the structure of the bone. Although DNA is not well preserved at acidic $\mathrm{pH}$, it is relatively stable at slightly alkaline or neutral $\mathrm{pH}$ (39). Studies have shown that dark, cool/cold, dry and anaerobic conditions are most favorable for the preservation of aDNA.

\subsection{Contamination}

One of the most important problem in aDNA research is contamination. Microorganism contamination and modern DNA contamination is frequently encountered in aDNA studies. Samples are constantly exposed to modern DNA while they are being removed from excavation sites and during anthropological studies. Gloves and other protective equipment must be used to minimize exposure. Otherwise contamination with modern DNA will occur, leading to false positive results and misconception. In addition to excavation and anthrolopological sites, samples may also be contaminated in the laboratory. An aDNA laboratory must be isolated and all devices, materials and consumables should only be used for aDNA research in order to prevent modern DNA contamination. All work must be done in a protective suit, with gloves and mask, in a sterile environment. $(2,40,41)$. In order to avoid modern DNA contamination, all staff (from the excavation team to laboratory staff) should be trained and necessary precautions must be taken.

\section{Conclusion}

Ancient DNA research has rapidly gained momentum with developing technologies. Studies of ancient samples have a huge potential to answer questions; from the molecular evolution of bacteria, microbiological genome changes throughout centuries, to resolution of criminal events or determination of migration routes of communities. In the future, problems encountered in obtaining ancient DNA will be more easily coped with further developments in technology and molecular methods. As research of aDNA samples increase, our interpretations will become more reflective of our history.

Conflict of Interest: No conflict of interest was declared by the authors.

Abbreviations: DNA, deoxyribonucleic acid; aDNA, ancient DNA; EDTA, ethylenediaminetetraacetic acid; HBV, Hepatitis B virus; PCIA, phenol-chloroform isoamyl alcohol; mtDNA, mitochondrial DNA; PCR, polymerase chain reaction.

Peer-review: Externally peer-reviewed.

\section{REFERENCES}

1. Singh J, Garg A. Ancient DNA analysis and its probable applications in forensic anthropology. J Punjab Acad Forensic Med Toxicol. 2014;14(1):43-50.

2. Tekeli E, Elma C. Antropolojik kemik örneklerinden antik DNA çalişmalari. 2016;32.

3. Higuchi R, Bowman B, Freiberger M, Ryder OA, Wilson AC. DNA sequences from the quagga, an extinct member of the horse family. Nature. 1984;312(5991):282-4.

4. Lindahl T. Instability and decay of the primary structure of DNA. Nature. 1993;362:709-15.

5. Hagelberg E, Hofreiter M, Keyser C. Ancient DNA: the first three decades. Philos Trans R Soc Lond B Biol Sci. 2015;370(1660):20130371. 
6. Goffeau A, Barrell G, Bussey H, Davis RW, Dujon $B$, et al. Life with 6000 genes. Science (80- ). 1996;274(5287):546-67.

7. Kchouk M, Gibrat JF, Elloumi M. Generations of Sequencing Technologies: From First to Next Generation. Biol Med. 2017;09(03).

8. Orlando L, Ginolhac A, Zhang G, Froese D, Albrechtsen $A$, et al. Recalibrating equus evolution using the genome sequence of an early Middle Pleistocene horse. Nature. 2013;499(7456):74-8.

9. Li R. Forensic Biology. 2nd ed. CRC Press; 2015. 567.

10. Elkins KM. Forensic DNA Biology : a Laboratory Manual, Chapter 4. Elsevier; 2012. 39-52.

11. Dabney J., Meyer M., and Pääbo S., Ancient DNA Damage. Cold Spring Harb Perspect Biol. 2013 Jul; 5(7): a012567.

12. Dabney J. and Meyer M., Extraction of Highly Degraded DNA from Ancient Bones and Teeth. Ancient DNA: Methods and Protocols, Methods in Molecular Biology. 2019;25-29 p.

13. Mühlemann B, Jones TC, Damgaard PDB, Allentoft ME, Shevnina I, et al. Ancient hepatitis $B$ viruses from the Bronze Age to the Medieval period. 2018.

14. Rasmussen S, Allentoft ME, Nielsen K, Nielsen $\mathrm{R}$, Kristiansen $\mathrm{K}$, et al. Early Divergent Strains of Yersinia pestis in Eurasia Article Early Divergent Strains of Yersinia pestis in Eurasia 5,000 Years Ago. 2015;163:571-82.

15. Spyrou MA, Tukhbatova RI, Wang CC, Valtueña AA, Lankapalli AK, Kondrashin VV., et al. Analysis of 3800-year-old Yersinia pestis genomes suggests Bronze Age origin for bubonic plague. Nat Commun. 2018;9(1):1-10.

16. Dobney K. Neanderthal behaviour, diet, and disease inferred from ancient DNA in dental calculus. 2017;(March).

17. Schlott $T$, Eiffert $H$, Schmidt-Schultz T, Gebhardt $M$, Parzinger $\mathrm{H}$, et al. Detection and analysis of cancer genes amplified from bone material of a Scythian royal burial in Arzhan near Tuva, Siberia. Anticancer Res. 2007;27(6 B):4117-9.

18. Cisneros L, Bussey KJ, Orr AJ, Miočević M, Lineweaver $\mathrm{CH}$, et al. Ancient genes establish stress-induced mutation as a hallmark of cancer. PLoS One. 2017;12(4):1-22.

19. Keller A, Graefen A, Ball M, Matzas M, Boisguerin $\checkmark$, et al. New insights into the Tyrolean Iceman's origin and phenotype as inferred by wholegenome sequencing. Nat Commun. 2012;3.

20. Rollo F, Ubaldi M, Ermini L, Marota I. Otzi's last meals: DNA analysis of the intestinal content of the Neolithic glacier mummy from the Alps. Proc Natl Acad Sci. 2002;99(20):12594-9.

21. Berens AJ, Cooper TL, Lachance J. The genomic health of ancient hominins. 2017;1-34.

22. Toncheva D., Serbezov D., Karachanak-Yankova S. and Nesheva D. Ancient mitochondrial DNA pathogenic variants putatively associated with mitochondrial disease. 2020; PLOS ONE

23. Mays S. Archaeological skeletons support a northwest European origin for Paget's disease of bone. J Bone Miner Res. 2010; 25(8):1839-41.

24. Shaw B., Burrell C.L., Green D. et.al. Molecular insights into an ancient form of Paget's disease of bone. PNAS 2019 ;116: 10463-10472.

25. Pilli E, Fox CL, Capelli C, Lari M, Sampietro L, et al. Ancient DNA and forensics genetics: The case of Francesco Petrarca. Forensic Sci Int Genet Suppl Ser. 2008;1(1):469-70.

26. Rizzi E, Lari M, Gigli E, Bellis G De, Caramelli D. Ancient DNA studies: new perspectives on old samples. 2012;1-19.

27. Muthukumar K, Nachiappan V. Cadmiuminduced oxidative stress in Saccharomyces cerevisiae. 2010;47(December):383-7.

28. Le Bihan $Y-V$, Izquierdo MA, Coste F, Aller $P$, Culard $F$, et al. 5-Hydroxy-5methylhydantoin DNA lesion, a molecular trap for DNA glycosylases. 2011;39(14):6277-90.

29. Höss $M$, Jaruga $P$, Zastawny $T H$, Dizdaroglu $M$, Pääbo S. DNA damage and DNA sequence retrieval from ancient tissues. 1996;24(7):13047.

30. Pääbo $S$, Poinar H, Serre $D$, Jaenicke-Despres $\mathrm{V}$, Hebler J, et al. Genetic analyses from ancient DNA. 2004.

31. Pääbo S. Ancient DNA: Extraction, characterization, molecular cloning, and enzymatic amplification. 1989;86(March):193943.

32. Lindahl T, Andersson A. Rate of Chain Breakage at Apurinic Sites Double-Stranded Deoxyribonucleic Acid. Biochemistry. 1972;11(19):3618-23.

33. Lindahl T, Nyberg B. Rate of Depurination of Native Deoxyribonucleic Acid. Biochemistry. 1972;11(19):3610-8. 
34. Morikawa K. DNA repair enzymes. Curr Opin Struct Biol. 1993;3(1):17-23.

35. Hedges REM. Bone diagenesis: An overview of processes. Archaeometry. 2002;44(3):319-28.

36. Yang DY, Watt K. Contamination controls when preparing archaeological remains for ancient DNA analysis. J Archaeol Sci. 2005;32(3):331-6.

37. Bollongino R, Vigne JD. Temperature monitoring in archaeological animal bone samples in the Near East arid area, before, during and after excavation. J Archaeol Sci. 2008;35(4):873-81.

38. Daskalaki E. Archaeological Genetics Approaching Human History through DNA Analysis. Digital Comprehensive Summaries of Uppsala Dissertations from the Faculty of Science and Technology; 1101. 2014. $61 \mathrm{p}$.

39. Stephan E. Patterns of chemical change in fossil bones and various states of bone presservation associated with soil conditions. Anthropozoologica. 1997;25-26(“Actes du 7ème Colloque international d'Archéozoologie"):17380.

40. Cooper A. Ancient DNA: Do It Right or Not at All. Science (80-). 2000;289(5482):1139b-1139.

41. Akis I. Antik DNA Çalışmaları ve Türkiye. J Cell Mol Biol. 2014;12(1-2):1-9. 